\title{
_†..
}

\section{Literatura surda: traduzindo histórias de vidas singulares}

\section{Deaf literature: translating singular life stories}

\author{
$\infty$ \\ Márcia Rios da Silva \\ Universidade do Estado da Bahia, Salvador, Bahia, Brasil \\ marciarios885@gmail.com \\ ○ \\ Jéssica Gabriela da Silva Penha \\ Universidade do Estado da Bahia, Salvador, Bahia, Brasil \\ professora.gabriela.penha@gmail.com
}

Resumo: A literatura surda emergente vem se destacando pela adaptação de histórias "originais" em paralelo a uma escrita autoral crescente. Na reescrita dessas produções originais, os surdos ganham visibilidade como sujeitos ativos e participativos no espaço social e cultural (PERLIN). Sob essa formação de apropriação cultural, a literatura surda assume o compromisso com a tematização de situações e sentimentos enfrentados pelo indivíduo surdo (GAVA), trazendo à tona o desejo de reconhecimento e reafirmação de identidades. Considerando o público ao qual se destinam às referidas adaptações, o presente artigo tem por objetivo proceder a uma reflexão sobre esta prática tradutória em que questões temáticas e formais são passíveis de atualização e recriação. Nesta análise, busca-se apoio nas contribuições de Marinyse Oliveira, Lodenir Karnopp e Linda Hutcheon, que postulam que os processos de adaptação e tradução estão imbricados e resultam em um trabalho de criação. 
Palavras-chave: Literatura surda. Criação. Adaptação. Tradução.

Abstract: The emerging deaf literature has been excelling in the adaptation of "original" stories in parallel with a growing authorial writing. In the rewriting of these original productions, deaf people gain visibility as active and participative individuals in the social and cultural space (PERLIN). Under this formation of cultural appropriation, deaf literature has been committed to the thematization of situations and feelings faced by deaf persons (GAVA), bringing to light the desire for recognition and reaffirmation of identities. Considering the target audience of these adaptations, this article aims to reflect about this translation practice in which thematic and formal issues are subject to renewal and recreation. In this analysis, we have sought support in the contributions of Marinyse Oliveira, Lodenir Karnopp, and Linda Hutcheon, who postulate that the adaptation and translation processes are intertwined and result in a work of creation.

Keywords: Deaf Literature. Creation. Adaptation. Translation.

Submetido em 10 de dezembro de 2020.

Aceito em 26 de março de 2021.

Publicado em 12 de novembro de 2021. 


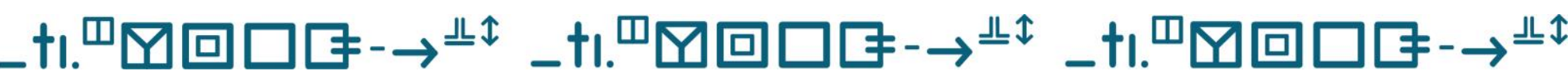

Literatura surda: traduzindo histórias de vidas singulares Márcia Rios da Silva • Jéssica Gabriela da Silva Penha

As inúmeras adaptações e traduções de textos literários para a comunidade leitora surda testemunham as constantes reivindicações, por reconhecimento, de sujeitos que, historicamente, foram excluídos da vida em sociedade. Os diferentes movimentos dos surdos, que emergiram inicialmente na Europa do século XIX, consolidaram a luta desses sujeitos por políticas públicas, levando-os a ganhar espaços sociais significativos. Em tais mobilizações, foram criadas estratégias, reivindicados espaços e direitos sociais para se reafirmar e valorizar diferenças identitárias, culturais e linguísticas, tendo como ponto distintivo entre o surdo e o ouvinte a língua de sinais. Não se pode ignorar o fato de que, por longas décadas, a língua de comunicação do surdo foi vista como mímica e gestos aleatórios que serviam apenas para transmitir mensagens com demandas ou necessidades básicas. Só com o surgimento dos movimentos e das escolas de surdos é que a concepção em torno da língua espacial-visual do não ouvinte modificou-se e passou a ser vista e valorizada como um sistema linguístico legítimo. Com o reconhecimento da legitimidade da língua de sinais, o surdo encontrou a possibilidade de ingressar no mundo da linguagem, sem a qual, de acordo com Michel Foucault (2007), o homem está fadado à incomunicabilidade de um universo desconhecido.

Não se pode ignorar, contudo, que, a despeito das conquistas significativas, os surdos ainda encontram grandes dificuldades em um mundo majoritariamente ouvinte e oralista. Por isso, a luta é contínua, como forma de fazer valer sua cultura e identidade em espaços formais e nãoformais de educação. Tais conquistas vão dar visibilidade para uma produção literária e artística produzida pelos surdos ou destinada a eles. Desde então, as mãos se tornaram falantes e se pôde ouvir seus movimentos, os quais delinearam os caminhos da literatura surda que, além de comunicar, assumiu o compromisso de apresentar uma identidade e 


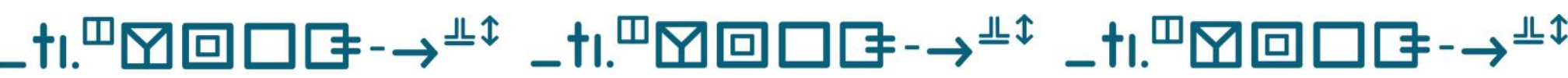

Literatura surda: traduzindo histórias de vidas singulares Márcia Rios da Silva • Jéssica Gabriela da Silva Penha

bilíngue, os vídeos têm sinalização em Libras e legendas em língua portuguesa e estão disponíveis gratuitamente no site do INES. A editora Arara Azul traduziu também o conto "A cartomante", de Machado de Assis, Iracema, de José de Alencar, e $O$ velho da horta, de Gil Vicente, além de histórias infantis, como Alice no país das maravilhas e Pinóquio.

Na produção literária surda emergente, em circulação no Brasil, as adaptações se tornaram um recurso altamente empregado, vindo a ser fundamental à comunidade de surdos e um artefato de grande visibilidade. Do século XIX aos dias atuais, essa prática tradutória tem ganhado espaço no contexto nacional, principalmente na literatura destinada às crianças.

No caso da literatura surda, trata-se de reescritas do acervo literário que trazem elementos da história "original" com temas e questões relacionados à cultura e à identidade surdas. Dentre essas adaptações, destaca-se o trabalho dos professores Lodenir Karnopp e Fabiano Rosa em parceria com a editora Ulbra/RS, em 2011, quando lançaram um projeto de adaptação de contos, destinados às crianças, para a comunidade surda. Das cinco adaptações na categoria de literatura surda, quatro são escritas e publicadas por Karnopp e Rosa: Cinderela surda, Rapunzel surda, Patinho surdo e Adão e Eva, com apenas uma, A cigarra surda e as formigas, feita por Carmem Oliveira e Jaqueline Boldo, professoras de surdos. Produzido manualmente, este livro ganhou as ilustrações de um aluno surdo. Do conjunto dessas produções, são dirigidas aos adultos: Tibi e Joca: uma história de dois mundos, da professora Cláudia Aqualti Bisol, pela Editora Mercado Aberto, em 2001, e o Som do silêncio, de Cláudia Cortes, pela Editora Lovise, em 2004.

É importante ressaltar que boa parte das produções textuais destinadas ao público adulto é divulgada por diferentes meios. Vão desde os mais tradicionais, como rodas de conversa, aos mais contemporâneos, a exemplo das produções audiovisuais publicadas na plataforma Youtube. As piadas e os 


\section{_t..}

Literatura surda: traduzindo histórias de vidas singulares Márcia Rios da Silva • Jéssica Gabriela da Silva Penha

poemas são recorrentes e circulam nas comunidades surdas. Poetas como Áulio de Nóbrega, Alan Henry, Nelson Pimenta e Fernando Machado utilizam as redes digitais para sinalizar seus poemas, e os de outros poetas surdos, e divulgar a arte e a cultura não-ouvinte. Tais produções tornam possível o protagonismo das mãos e do surdo. Nelas, ele é o espectador, o poeta, o intérprete e o defensor da sua língua. Por isso, a grande maioria das produções revela a militância e a busca incessante dos surdos por espaços e reconhecimento de suas identidades. Com sua arte, os artistas surdos têm a possibilidade de se apresentar ao mundo, empregando sua primeira língua como a língua de divulgação e expressão das suas criações, formando e reafirmando sua cultura e identidade, trazendo aspectos culturais para o universo literário. Assim, transformam-se em sujeitos ativos e participativos no espaço social e cultural.

Ainda na esfera do audiovisual, o cinema também captou os anseios e demandas do universo surdo, criando personagens surdos marcantes. Dentre os filmes, destacam-se Filhos do silêncio (1986), Adorável professor (1995), O milagre de Anne Sullivan (2000), Babel (2006), Nada que eu ouça (2008), The hammer (2010), A família Bélier (2014) e A forma da água (2017). Este último tem como protagonista Elisa Esposito, uma personagem surda, conhecedora da cultura surda norte-americana, que utiliza e ensina a ASL, a Língua de Sinais Americana. Tais filmes tematizam questões identitárias e da cultura surda, ressaltando a língua de sinais e reafirmando a necessidade do nãoouvinte em se reconhecer surdo. Sobre o reconhecer-se surdo, Gladis Perlin (2003, p. 90) afirma que a valorização dessa atitude significa 


\section{-†ı.}

Literatura surda: traduzindo histórias de vidas singulares Márcia Rios da Silva • Jéssica Gabriela da Silva Penha

[...] que estamos sendo o outro com nossa alteridade. Somos o surdo, o povo unânime reunido na auto-presença da língua de sinais, da linguagem que evoca uma diferença de outros povos, da cultura visual, do jeito de ser. Somos alteridades provadas pela experiência, alteridades outras. Somos surdos!

No âmbito da cultura digital, as produções destinadas às comunidades surdas se expandiram significativamente. Em 2018, o artista Paulo Henrique dos Santos, que trabalha com animação, lançou o primeiro desenho animado totalmente em Libras, Min e as mãozinhas. O filme foi lançado na plataforma Youtube, em 26 de setembro, dia nacional do surdo, alcançando mais de 450 mil visualizações (SANTOS, 2018). Esse largo êxito de público levou ao lançamento de uma série de novos episódios.

As redes sociais do mundo digital auxiliaram o surdo na divulgação da sua língua e cultura. Em 2015, os gaúchos Francielle Cantarelli e Fábio Cantarelli, ambos surdos, criaram no Facebook a página O diário de Fiorella, para auxiliar pais surdos com crianças surdas. Fiorella, filha do casal, nasceu surda e, desde o nascimento, foi estimulada a se comunicar em Libras. Os vídeos mostram a evolução comunicativa da menina, que alcançou plena fluência em Libras e já começa a ser apresentada à língua portuguesa por meio da datilologia (alfabeto manual em Libras) das palavras.

Outros canais e páginas nas redes sociais reúnem surdos e amantes de Libras, a exemplo de Libras mais, Libras avante, Libras tudo, Libras com amor, Mãos tagarelas. Há também um aplicativo que auxilia o aprendizado da Libras, o Hand Talk. Neste, o usuário escreve ou fala a palavra em português e o boneco Hugo a traduz para a Libras.

Como se pode inferir, a cultura surda sempre esteve perto do outro, que é o ouvinte, em todos os âmbitos e lugares, impulsionada pelo desejo do encontro, do reconhecimento e da reafirmação contínua do que se é. Por esse entendimento, as produções artísticas surdas nos convidam a pensar 


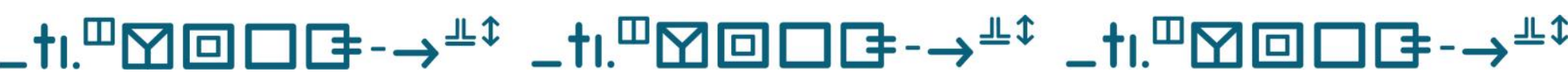

Literatura surda: traduzindo histórias de vidas singulares Márcia Rios da Silva • Jéssica Gabriela da Silva Penha

na função da literatura como um artifício de apropriação cultural. A partir do momento em que o surdo se reconhece e apresenta sua cultura, sua produção literária com um rosto e um nome, o ouvinte é levado a reconhecer traços de um grupo que deseja divulgar seus modos de viver e estar no mundo. Nesse sentido, a língua de sinais se torna legitimada, vindo a ser reconhecida também como linguagem que insere o ser humano no mundo.

Segundo Águida Aparecida Gava, a literatura surda compromete-se a “[...] oferecer registros de situações e sentimentos enfrentados pelo indivíduo surdo, além de imprimir graça e suavidade ao discurso, ampliando o vocabulário e proporcionando reflexões profundas ao leitor" (GAVA, 2015, p. 63). E para que ocorram processos de identificação, é importante que a criação ou adaptação de uma história considere aspectos, conflitos, sentimentos e sensações vividos por aquele grupo em particular. Quando se trata de adaptações, deve-se preservar a temática do texto original. Sobre essa questão, Marinyze Prates de Oliveira (2004, p. 42), pesquisadora de literatura e cinema, afirma que

[...] cada adaptação impregna e revela os traços de uma atividade de tradução que, se por um lado guardará sempre algum vínculo formal ou temático com a obra que the deu origem - mesmo quando lhe subverte o sentido -, por outro corresponderá a uma construção regida por princípios muito próprios, que devem conferir-Ihe autonomia em relação ao texto base e sustentá-la enquanto obra.

A recorrência a adaptações e a traduções de obras literárias para a comunidade surda impõe aqui algumas reflexões sobre tais processos. Segundo Lodenir Karnopp (2008), é necessário estabelecer diferença entre as traduções feitas para Libras e as histórias e adaptações que falam do universo surdo. Assim, quando se trata de uma adaptação, não é suficiente transcrever o alfabeto em língua de sinais, processo denominado datilologia. 


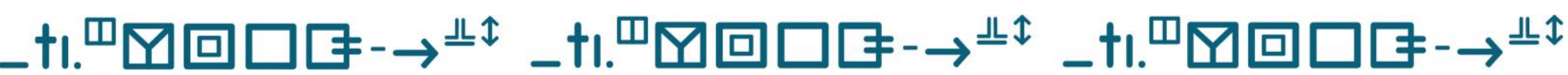

Literatura surda: traduzindo histórias de vidas singulares Márcia Rios da Silva • Jéssica Gabriela da Silva Penha

Deve-se privilegiar o diálogo entre a história original e o universo que se deseja ficcionalizar. Por isso, a temática surda torna-se tão determinante nas produções literárias destinadas às pessoas surdas e naquelas de autoria desses sujeitos.

\begin{abstract}
A literatura surda está relacionada com a cultura surda. A literatura da cultura surda, contada na língua de sinais de determinada comunidade lingüística, é constituída pelas histórias produzidas em língua de sinais pelas pessoas surdas, pelas histórias de vida que são frequentemente relatadas, pelos contos, lendas, fábulas, piadas, poemas sinalizados, anedotas, jogos de linguagem e muito mais. 0 material, em geral, reconta a experiência das pessoas surdas, no que diz respeito, direta ou indiretamente, à relação entre as pessoas surdas e ouvintes, que são narradas como relações conflituosas, benevolentes, de aceitação ou de opressão do surdo (KARNOPP, 2008, p. 15).
\end{abstract}

De acordo com Linda Hutcheon (2006), em seus estudos sobre narração e adaptação, esse último fenômeno se apresenta como um palimpsesto, termo cujo emprego tem início na Idade Média. Material reaproveitável, o palimpsesto era um manuscrito em pergaminho que os copistas apagavam, para nele escrever de novo. Para Hutcheon, a adaptação é produto e processo, ou seja, um trabalho de transcodificação. Muitos textos literários, já tão conhecidos do público leitor, abrem espaço para outras releituras, trazendo novos personagens, novas culturas e novos conceitos. Desse modo, a obra original é reescrita:

Conceber a adaptação como adaptação é pensá-la como um palimpsesto. Para quem conhece a obra fonte, ela permanece uma sombra na adaptação. Ao chamar um trabalho de adaptação, se pensa automaticamente em sua relação com outra obra. No entanto, este fato não implica na adaptação como uma obra que não possa ser autônoma (HUTCHEON, 2006, p. 6). 


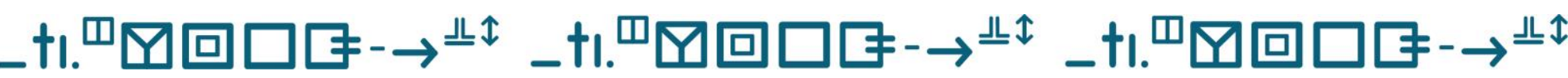

Literatura surda: traduzindo histórias de vidas singulares

Márcia Rios da Silva • Jéssica Gabriela da Silva Penha

Para essa estudiosa, a adaptação é "[...] um trabalho que vem em segundo lugar, mas sem ser secundário" (HUTCHEON, 2006, p. 9) e a sua beleza está no ato de recontar, de acrescentar um ponto de vista a uma obra que, embora já existente, não é acabada. Sendo assim, um texto literário como $O$ patinho surdo, de autoria de Karnopp e Rosa, destinado aos surdos, consiste em uma adaptação, uma vez que, inicialmente, efetivou-se uma interpretação criativa da chamada história original - a qual é uma visão dos autores sobre a obra lida -, seguida de um trabalho inventitvo que avalia, interpreta e transcreve as obras originais com as mudanças necessárias.

Segundo Linda Hutcheon (2006), a interpretação compreende a recriação e a reinterpretação, o que também é chamado de apropriação e "salvaging" (aproveitamento). Para a autora, o salvaging, um processo receptivo, pode ser lido como intertextualidade: "a adaptação como um processo receptivo é uma forma de intertextualidade, já que a vivenciamos como palimpsestos, que vivem através da memória que temos de outras obras" ( $p$. 8). As reflexões dessa pesquisadora contribuem para que se desfaça uma visão preconceituosa acerca das adaptações, as quais, durante um largo tempo, foram julgadas como produções menores, tidas como cópias, portanto, sem originalidade. Ainda por essa visão, com as adaptações, tem-se a perda da "aura" da obra original. Para Marinyze Oliveira (2004, p. 31), é fundamental "despojar o objeto do seu véu" da ilusória ideia de pureza e originalidade. A própria Hutcheon (2006) defende que as adaptações são intertextos, processos de filtragem dotados de liberdade para recriar, parafrasear e inserir novos elementos nas obras que as precedem.

Os trabalhos de adaptação como os efetivados por Karnopp e Rosa alcançaram o que Linda Hutcheon designa de processo de apropriação. Em tal processo, tem-se inicialmente uma interpretação, seguida da adaptação, como um trabalho criativo, com a intenção de suplantar, seja no plano 


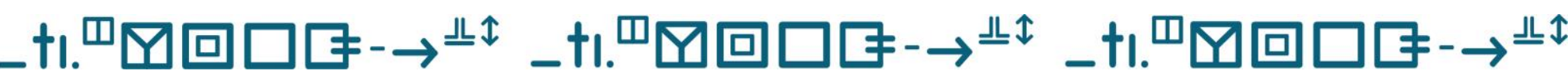

Literatura surda: traduzindo histórias de vidas singulares Márcia Rios da Silva • Jéssica Gabriela da Silva Penha

histórico, seja no plano cultural, produções literárias existentes. Desse modo, as adaptações podem apresentar um novo contexto estético, político e cultural da obra que a precedeu. Os textos da tradição oral, populares, por exemplo, são frutos de adaptações dos contos orais que circulavam nas ruas de cidades europeias. É interessante observar que as primeiras adaptações destinadas para crianças são datadas a partir do século XVII, quando, aliado à burguesia (nova noção de família, centrada em um núcleo unicelular), emerge o conceito de infância e, consequentemente, o de criança. A burguesia separou a infância da idade adulta, vendo aquela como uma faixa etária diferenciada, com interesses próprios e necessitando de formação específica.

Um aspecto bastante pertinente, levantado por Linda Hutcheon, é que, para se experienciar uma adaptação como adaptação, é necessário reconhecê-la como tal. Contudo, o reconhecimento nem sempre é imediato, depende, sem dúvida, do conhecimento prévio da história que foi traduzida. Cada adaptação bem realizada, independente do seu formato, nas várias linguagens, favorece e alcança grande número de leitores que se voltam, ou não, para os textos que a precederam. No entanto, não é possível ver as adaptações apenas como caminho, ou caminho certeiro, aposta exata, confirmação inquestionável de acesso aos originais, porque pode não se chegar ao "original". Ou seja, pode acontecer de não se reconhecer uma adaptação como adaptação porque, pelo desconhecimento, considerá-la como uma produção original.

É nessa perspectiva que Linda Hutcheon afirma que não há necessidade de adaptações fiéis, pois cada uma é feita com uma finalidade: "Assim como não existe tradução literal, também não há adaptação literal. A mudança para meios diferentes ou para outra língua sempre irá significar perdas e ganhos" (HUTCHEON, 2006, p. 16). As adaptações têm a liberdade de alterar o 


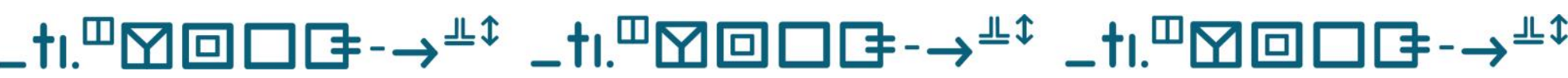

Literatura surda: traduzindo histórias de vidas singulares Márcia Rios da Silva • Jéssica Gabriela da Silva Penha

desenrolar da história, a temática, o ponto de vista, o foco narrativo. É o que acontece com algumas adaptações para leitores surdos, em que a temática é modificada tendo em vista o contexto cultural do surdo, levando o enredo a se desenrolar de modo diferente, e nas quais se acrescentam personagens fundamentais da cultura surda. Por isso, há diferenças básicas entre adaptação e tradução. Muitos textos literários da cultura ouvinte foram traduzidos para Libras, processo em que a história é contada exatamente como a original, mas em língua de sinais. Para alguns estudiosos, esse tipo de trabalho não pode ser considerado adaptação.

Outra forma de adaptação é a intersemiótica, em que se transpõe um texto para um novo meio, por exemplo, a transformação de uma história em quadrinhos em desenho animado, a encenação de um texto dramático, a transposição de um romance para o cinema. Pode-se considerar ainda adaptação a modificação de determinado texto para atender às demandas de um novo público-alvo, como acontece com as adaptações para pessoas surdas. No âmbito dos estudos da tradução, Bastin (2011, p. 3) define a adaptação como um procedimento tradutório: "A adaptação pode ser entendida como um conjunto de intervenções tradutórias que resultam em um texto, geralmente não aceito como tradução, mas reconhecido como representante de um texto fonte" ${ }^{\prime 1}$. Tal procedimento abre espaço para acréscimos, omissões, criações, adequações culturais, e assim por diante, de modo a gerar um novo texto que seja culturalmente aceito ou, ainda, que seja, em especial, direcionado ao público-alvo pressuposto, no caso em questão, os surdos.

Algumas traduções literárias encontradas na Internet, seja para crianças, seja para adultos, apresentam-se como produções em que o texto de chegada pode modificar estruturas, categorias gramaticais e semânticas e tipos de discurso para melhor servir ao público receptor, por meio da eliminação das marcas da língua. Como a Libras possui uma estrutura gramatical 


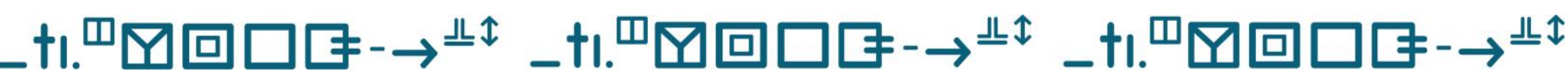

Literatura surda: traduzindo histórias de vidas singulares Márcia Rios da Silva • Jéssica Gabriela da Silva Penha

diferente da língua portuguesa, é fundamental que essas alterações ocorram. Apesar das diferenças entre uma atividade e outra, Marinyze Oliveira (2004, p. 46) acredita que toda adaptação revela traços de uma atividade de tradução:

[...] cada adaptação impregna e revela traços de uma atividade de tradução que, se por um lado guardará sempre um vínculo com o formal ou temático com a obra que lhe deu origem - mesmo quando lhe subverte o sentido -, por outro corresponderá a uma construção regida por princípios muito próprios, que devem conferir-Ihe autonomia em relação ao texto-base e sustentá-la enquanto obra. ${ }^{2}$

As razões para se recorrer à adaptação podem ser de cunho cultural, político, pessoal ou motivadas para alcançar um novo público-alvo que, uma vez definido, norteará as regras desse processo de adaptação. Em primeiro lugar, deve-se delimitar o elemento da obra original a ser adaptado, seja sua temática, seja seu estilo. Por fim, deve-se tratar da adaptação de aspectos relativos à época, ao lugar, à sociedade e à cultura nas quais a história se passa. Com essas questões em mente, o trabalho de adaptação ganha sistematicidade, o que não garante, porém, uma recepção aprovativa. Em síntese, é possível identificar duas abordagens da prática da adaptação. Por um lado, tal prática é vista como um fenômeno amplo, que se dá em uma mesma língua, que adquire esse "rótulo" justamente por tratar-se de um fenômeno global. Por outro, o processo de adaptação é concebido em estreita ligação com a tradução, representando uma variante dela, bem como uma condição à existência.

É preciso ressaltar mais uma vez a importância da adaptação na literatura destinada às crianças e nas produções surdas e o seu valor como prática tradutória. Ambos os conceitos e práticas, adaptação e tradução, estão 


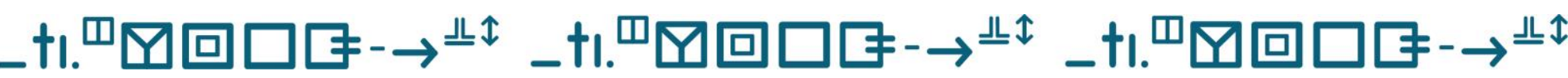

Literatura surda: traduzindo histórias de vidas singulares Márcia Rios da Silva • Jéssica Gabriela da Silva Penha

estreitamente relacionados. No entanto, o limite dessa relação e o status de conceito e prática dependerão, inevitavelmente, de fatores socioculturais e históricos, bem como da resposta do público e da crítica ao texto traduzido ou adaptado. Essa prática apresenta marcas explícitas de intertextualidade, ou seja, estabelece relação assumida com um texto determinado, modificando-o, tanto para reafirmá-lo quanto para rejeitá-lo. Como procedimento técnico, a adaptação recebe essa denominação, técnica tradutória ou prática independente, que envolve mudanças de meios, gêneros, de relações de espaço e tempo e, em grande parte das vezes, de receptores. Partindo desse viés de adaptação como fenômeno mais amplo, é possível começar a pensar em procedimentos técnicos da adaptação e da sua importância para a literatura infantil e surda.

O processo de recontar histórias envolve, necessariamente, atos de tradução ou adaptação. Quando uma pessoa surda aprende uma história em uma comunidade ouvinte, como a do patinho feio, e a reconta em língua de sinais na sua comunidade, ela a traduz de uma língua para outra, fazendo as transformações inevitáveis, impostas, para dizer o mínimo, pelas marcantes diferenças entre uma língua oral-auditiva, como o português, e uma língua visual-espacial, como a Libras. Pode, ainda, fazer transformações acentuadas no texto de partida, se quiser trazer para a história sinalizada elementos culturais do novo público. Nesse caso, realiza uma adaptação. Pode então, como é fato, transformar o personagem patinho em um patinho surdo.

É fundamental ressaltar que, apesar de muitas adaptações, entre as produções literárias surdas encontram-se exemplos de adaptações, traduções e criações. É inegável que a literatura surda amplia ainda mais noções e atividades tradutórias já bastante complexas e amplas, como é o caso da tradução oral/sinalizada que, tradicionalmente, denomina-se interpretação (simultânea ou consecutiva), ou dos usos do termo adaptação em referência 


\section{_tı.}

Literatura surda: traduzindo histórias de vidas singulares Márcia Rios da Silva • Jéssica Gabriela da Silva Penha

à obras derivadas de obras anteriores, adaptadas a um novo público ou a uma nova mídia (por exemplo, um romance clássico reescrito em versão infanto-juvenil, em quadrinhos ou em versão cinematográfica). Portanto, as adaptações são artefatos literários que corroboram para legitimação e concretização da literatura surda.

Sobre as adaptações para a comunidade surda, muitos estudiosos as consideram necessárias, já que proporcionam o acesso e o conhecimento das obras originais para um público específico. Em relação à literatura surda, as adaptações se tornam imprescindíveis ao processo de constituição identitária e de representação de um determinado grupo que vive às margens. Por esse entendimento, não basta ler uma produção consagrada pela tradição literária. Antes, é importante se sentir representado e se reconhecer nas personagens. Por isso, graças a essas adaptações, a literatura surda deu voz a um público que há muito vivia no silêncio. Com elas, amplia-se o repertório de leituras, as quais se podem somar um número expressivo de produções autorais de sujeitos surdos, traduzindo para uma comunidade ampliada de leitores de um universo rico de experiências de vidas singulares.

\section{Referências}

BASTIN, Georges. Adaptation (1998). In: BAKER, M; SALDANHA, G. (orgs.). Routledge encyclopedia of translation studies. 2. ed. London: Routledge, 2011, p. 3-6.

FOUCAULT, Michel. A ordem do discurso: aula inaugural no Collège de France, pronunciada em 2 de Dezembro de 1970. 15. Ed. São Paulo: Loyola, 2007.

GAVA, Águida Aparecida. Breves considerações sobre a literatura surda. In: Acta Semiotica et Lingvistica. Vol. 20, n. 2, 2015. Disponível em 


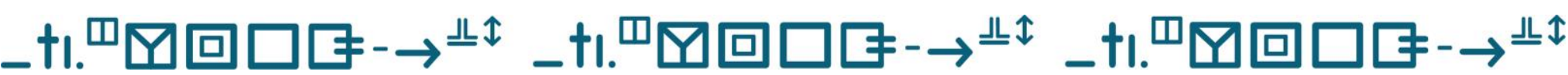

Literatura surda: traduzindo histórias de vidas singulares

Márcia Rios da Silva • Jéssica Gabriela da Silva Penha

https://periodicos.ufpb.br/index.php/actas/article/view/27945. Acesso em 30 abri 2019. P. 61-76.

HUTCHEON, Linda. Uma teoria da adaptação. Tradução André Cechinel. $2^{a}$. ed. Florianópolis, UFSC, 2006.

KARNOPP, Lodenir. Literatura surda. Centro de Comunicação e Expressão.

UFSC. $\quad$ Florianópolis. $2008 . \quad$ Disponível em https://www.libras.ufsc.br/colecaoLetrasLibras/eixoFormacaoEspecifica/liter aturaVisual/assets/369/Literatura_Surda_Texto-Base.pdf. Acesso em 12 set 2020.

OLIVEIRA. Marinyze Prates de. Olhares roubados: cinema, literatura e nacionalidade. Salvador: Quarteto, 2004.

PERLIN, Gladis. O ser e o estar sendo surdos: alteridade, diferença e identidade. Tese (Doutorado em Educação). Universidade Federal do Rio Grande do Sul: Porto Alegre, 2003.

SANTOS, Paulo Henrique dos. Min e as mãozinhas. 2018. Disponível em https://www.youtube.com/watch?v=zNCczm3jzgo. Acesso em 30 out 2020.

\section{Notas}

\footnotetext{
${ }^{1}$ Tradução nossa. Original: "Adaptation may be understood as a set of translative interventions which result in a text that is not generally accepted as a translation but is nevertheless recognized as representing a source text". (BASTIN, 2011, p. 3).

${ }^{2}$ Com base em Roman Jakobson, a autora tipifica as traduções: interlingual, intralingual e intersemiótica. As duas primeiras ocorrem com as interpretações dos signos de uma língua para outra; a intersemiótica, que acontece com muitas traduções para Libras, consiste na transposição de um sistema de signo para outro (OLIVEIRA, 2004).
}

\section{Publisher}

UNIVERSIDADE FEDERAL DE GOIÁS. CURSOS DE LETRAS: LIBRAS E DE LETRAS: TRADUÇÃO E INTERPRETAÇÃO EM LIBRAS/PORTUGUÊS DA 
